\section{Tyndall, John}

T. Arndt

Bioscientia Institut für Medizinische Diagnostik $\mathrm{GmbH}$, Ingelheim, Deutschland

Lebensdaten Britischer Physiker, geboren am 02. August 1820 in Leighlin Bridge (Irland), gestorben am 04. Dezember 1893 in Hind Head (England)
Verdienste Studium in Marburg und Berlin. Physiker und Naturphilosoph. Untersuchungen über lichtempfindliche Gase, Lichtpolarisation, Diamagnetismus, Wärmestrahlung, Schallfortpflanzung und Thermoelektrizität. Genauere Beschreibung des von Faraday im Jahr 1857 entdeckten, später als „Faraday-Tyndall-Effekt", oft nur noch $>$ Tyndall-Phänomen bezeichneten Effekts der Lichtstreuung in kolloidalen Lösungen, der Grundlage der $>$ Immunnephelometrie und Immunturbidimetrie ist. 